\title{
In-vitro Application of Doxorubicin Loaded Magnetoplasmonic Thermosensitive Liposomes for Laser Hyperthermia and Chemotherapy of Breast Cancer
}

\author{
Mohammad E Khosroshahi ${ }^{1,2 *}$, Lida Ghazanfari ${ }^{1,3}$, Zahra Hassannejad ${ }^{4}$ and Steven Lenhert ${ }^{3}$ \\ ${ }^{1}$ Laser and Nanobiophotonics Laboratory, Faculty of Biomedical Engineering, Amirkabir University of Technology, Tehran, Iran \\ ${ }^{2}$ Center for Advanced Diffusion-Wave Technologies (CADIFT), Department of Mechanical and Industrial Engineering, University of Toronto, Toronto, Canada \\ ${ }^{3}$ Department of Biological Sciences, Florida State University, Tallahassee, Florida, USA \\ ${ }^{4}$ Sina Trauma and Surgery Research Center, Tehran University of Medical Sciences, Tehran, Iran
}

\begin{abstract}
We describe doxorubicin loaded magnetoplasmonic thermosensitive liposomes (MPTL-DOX), which are designed to combine features of magnetic drug targeting and laser hyperthermia-triggered drug release. The synthesized magnetite/gold nanoshells are stabilized using polyvinyl pyrolidone (PVP) with mean crystallite size of $15.8 \pm 3.5 \mathrm{~nm}$. The liposome formulation DPPC:cholesterol:DSPE-PEG2000 at 80:20:5 molar ratio shows DOX release of less than $5 \%$ at $37^{\circ} \mathrm{C}$ following $24 \mathrm{~h}$ incubation. MPTL-DOX shows encapsulation efficiencies of about $95 \%$ and $74 \%$ for DOX and magnetoplasmonic nanoshells (MPNS), respectively. The MPTL-DOX formulation displays a desired temperature sensitivity with $65 \%$ and $100 \%$ DOX release following laser irradiation and then $24 \mathrm{~h}$ incubation at $37^{\circ} \mathrm{C}$, respectively. The rate of DOX release from liposome using this formulation is 0.09 which was obtained by heating to $43^{\circ} \mathrm{C}$, and agrees well with the first kinetic model. A temperature rise between $4-12^{\circ} \mathrm{C}$ was achieved for MNS using $25 \mu \mathrm{g} / \mathrm{ml}$ and $300 \mu \mathrm{g} / \mathrm{ml}$ after $400 \mathrm{~s}$ respectively. For cytotoxicity measurement, one untreated (control) and two treatment groups are studied. The first treatment groups are: with MPNS only, with MPTL only, and laser irradiation only. The second treatment groups are: laser hyperthermia using MPTL, MPTL with magnetic field (MF), MPTL-DOX, and MPTL-DOX with MF. MPTL-DOX is targeted to breast cancer cell lines (MCF-7 cells) under a permanent magnetic field and exhibits a substantial increase in cytotoxicity and apoptotic effects. The results suggest that externally guided drug targeting can trigger drug release using an exogenous absorber in laser hyperthermia which can be used advantageously for thermo-chemotherapy of cancers.
\end{abstract}

Keywords: Magnetoplasmonic nanoshells; Doxorubicin; Thermosensitive liposome; Laser hyperthermia; MCF-7 breast cancer cells; Cytotoxicity

\section{Introduction}

Engineered nanomaterials hold great promise in drug delivery systems [1-3]. Novel magnetic nano-formulations such as liposomes, metallic/nonmetallic, and polymeric nanoparticles have increased the ability to deliver drugs for which conventional therapies have shown limited efficacy. When magnetoliposomes containing iron oxide nanoparticles are exposed to a magnetic field the liposomal temperature exceeds transition temperature and the contents are released [4]. Heating techniques may be improved by using a magnetic field localized to therapeutic site, for instance a tumor [5-7]. Hassannejad et al. have recently demonstrated that gold-coated superparamagnetic iron oxide nanoparticles (SPIONs) encapsulated by phospholipid liposomes can be used as exogenous absorber in laser thermal therapy [8]. Moreover, gold nanoparticles were conjugated with the anticancer drug Doxorubicin, for drug delivery to liver cancer recently [9]. When gold nanostructures are irradiated by laser, the absorbed optical energy raises their temperature, hence acting as a localized heat source that is quickly equalized within the nanoparticles. The heat is then transferred to the surrounding environment determined by their thermal relaxation time and laser pulse duration. Therefore, light-triggered thermal properties of liposomal Au nanostructures are different from the classical thermosensitive liposomes [10]. Au nanostructures absorb energy at a characteristic wavelength and exhibit surface plasmon resonance (SPR) [11,12]. Only part of the absorbed energy is emitted as photoluminescence while most of it is converted to heat [13]. Therefore, light-induced heating of liposomal Au nanostructures by $\mathrm{UV}$, visible and near-infrared to release liposome-entrapped drugs has developed [14].

In addition to the required elements for triggered drug release, an optimized delivery system for cytotoxic drugs should have biophysical properties (e.g. stealth properties) to favour passive accumulation in tumors upon intravenous administration. This study is a novel approach towards implementing a PEG-shielded thermosensitive liposome encapsulating the DOX as a drug together with PVPstabilized magneto-plasmonic nanoshells (MPNS), enabling magnetic drug targeting by static gradient magnetic fields and laser hyperthermia as a trigger for drug release, producing a synergistic cytotoxic effect. To the best of our knowledge, this combination of magnetic targeting/ laser hyperthermia/drug release is novel and has not been addressed previously.

*Corresponding author: Mohammad E Khosroshahi, Center for Advanced Diffusion-Wave Technologies (CADIFT), Department of Mechanical Engineering and Industry, University of Toronto, M5S 3G8, Canada, Tel: 1-416-978-1287; E-mail: khosrom@mie.utoronto.ca

Received April 10, 2015; Accepted May 18, 2015; Published June 02, 2015

Citation: Khosroshahi ME, Ghazanfari L, Hassannejad Z, Lenhert S (2015) In-vitro Application of Doxorubicin Loaded Magnetoplasmonic Thermosensitive Liposomes for Laser Hyperthermia and Chemotherapy of Breast Cancer. J Nanomed Nanotechnol 6: 298. doi:10.4172/2157-7439.1000298

Copyright: (C) 2015 Khosroshahi ME, et al. This is an open-access article distributed under the terms of the Creative Commons Attribution License, which permits unrestricted use, distribution, and reproduction in any medium, provided the original author and source are credited. 
Citation: Khosroshahi ME, Ghazanfari L, Hassannejad Z, Lenhert S (2015) In-vitro Application of Doxorubicin Loaded Magnetoplasmonic Thermosensitive Liposomes for Laser Hyperthermia and Chemotherapy of Breast Cancer. J Nanomed Nanotechnol 6: 298. doi:10.4172/21577439.1000298

Page 2 of 9

\section{Materials and Methods}

\section{Chemicals and reagents}

All analytical reagents are used without further purification. Ferric chloride hexahydrate $\left(\mathrm{FeCl}_{3} .6 \mathrm{H}_{2} \mathrm{O}, 99 \%\right)$, ferrous chloride tetrahydrate $\left(\mathrm{FeCl}_{2} .4 \mathrm{H}_{2} \mathrm{O}, 99 \%\right)$, hydrochloric acid $(\mathrm{HCl}, 37 \%)$, sodium hydroxide, chloroform, formaldehyde solution $\left(\mathrm{H}_{2} \mathrm{CO}, 37 \%\right)$, absolute ethanol, Triton X-100, and polyvidone25 are purchased from Merck (USA). Tetrakis (hydroxymethy1) phosphonim chloride (THPC) aqueous solution, Gold (III) chloride trihydrate $\left(\mathrm{HAuCl}_{4} \cdot 3 \mathrm{H}_{2} \mathrm{O}\right.$, $\geq 49 \%$ Au basis), 3-aminopropyltriethoxysilane (APTES), and Doxorubicin hydrochloride (DOX) are purchased from SigmaAldrich (USA). Dipalmitoylphosphatidylcholine (DPPC), cholesterol (Chol), and 1,2-distearoyl-sn-glycero-3-phosphoethanolamine-N[amino(polyethylene glycol)-2000] (ammonium salt) (DSPEPEG2000) are purchased from Avanti Polar Lipids (USA). MCF-7 cell line is purchased from the Pasteur Institute (Iran). RPMI 1640 medium and fetal bovine serum (FBS) are purchased from GIBCO (USA). Annexin-V-FLUOS staining kit is purchased from Roche (Switzerland). Deionized water (18 M $\Omega . c m)$ is provided by a Milli-Q system and deoxygenated by vacuum for 1 hour prior to the use.

\section{Synthesis of PVP-stabilized gold nanoshells}

Gold coated superparamagnetic iron oxide nanoparticls (SPIONs) are fabricated by a multistep procedure as described earlier $[15,16]$. Briefly, SPIONs are synthesized by the coprecipitation method [17-19]. Then the surface of SPIONs is functionalized with APTES to generate an amine terminated surface [20]. A colloidal gold solution containing $\sim 2 \mathrm{~nm} \mathrm{Au}$ particles is prepared according to the Duff and Baker [21] method. After that, a continuous gold shell is grown around the SPIONs. In order to prepare PVP-coated gold nanoshells, in a typical procedure [8], the obtained nanoshell dispersion in water $(2 \mathrm{ml})$ is centrifuged at $4000 \mathrm{~g}$ for $25 \mathrm{~min}$. Then $1 \mathrm{ml}$ supernatant is replaced by $1 \mathrm{ml}$ PVP solution and the obtained mixture stirred for 24 hours at room temperature. After that, it is centrifuged twice under $4000 \mathrm{~g}$ for $25 \mathrm{~min}$ and washed with water in order to remove free PVP. As the hydrophilic head group $(\mathrm{N}-\mathrm{C}=\mathrm{O})$ of PVP is attached to the surface of the particles, particle repulsion will occur due to steric interactions between polymers adsorbed on the particle's surface.

\section{Preparation of magnetoplasmonic liposomes}

Liposomes are composed of DPPC:Chol:DSPE-PEG2000 at a molar ratio of 80:20:5, as suggested by Pradhan et al. [22]. A lipid mixture of chloroform stocks is prepared and dried at $42^{\circ} \mathrm{C}$ under nitrogen stream and further placed in a vacuum overnight. The lipid film is hydrated with a buffer consisting of PVP-coated gold nanoshell dispersed in $300 \mathrm{mM}$ Citrate $(\mathrm{pH} 4.0)$ at $60^{\circ} \mathrm{C}$. After hydration, $15 \mathrm{~min}$ of sonication (Tecna 20,190 W) is applied to break down any larger vesicles. Subsequently, the samples undergo 5 cycles of freeze-thaw including $10 \mathrm{~min}$ at $-196^{\circ} \mathrm{C}, 10 \mathrm{~min}$ at $65^{\circ} \mathrm{C}$ and $30 \mathrm{~s}$ vortexing between cycles. Unencapsulated nanoparticles are removed by centrifuging at $400 \mathrm{~g}$ for $5 \mathrm{~min}$, after which the supernatant liposomal dispersion is centrifuged at $20000 \mathrm{~g}$ for $30 \mathrm{~min}$ to precipitate the liposomes encapsulating gold nanoshells. Liposomes are obtained by extruding the mixture 15 times with an extruder (Avanti Polar Lipids) at $55^{\circ} \mathrm{C}$ through polycarbonate membrane filters (Whatman PLC, Maidstone, Kent) with a pore size of $100 \mathrm{~nm}$. Encapsulation efficiency of MPTL is calculated using ICP-MS results through the formula $\left(\mathrm{W}_{1} / \mathrm{W}\right) \times 100 \%$, where $\mathrm{W}$ is initial concentration of $\mathrm{Fe}(\mathrm{mg} / \mathrm{ml})$ in hydration solution and $\mathrm{W}_{1}$ is encapsulated concentration of $\mathrm{Fe}(\mathrm{mg} / \mathrm{ml})$ in the liposomes.

\section{Doxorubicin loading into the magnetoplasmonic liposomes (MPTL-DOX)}

Doxorubicin, a weak base cation with a $\mathrm{pKa}$ of 8.3 , is encapsulated into the extruded liposomes using a $\mathrm{pH}$-gradient loading protocol as described by Mayer et al., [23] with a slight modification: the exterior $\mathrm{pH}$ of the extruded liposomes is adjusted to 8 with sodium carbonate solution $(500 \mathrm{mM})$ creating a $\mathrm{pH}$ gradient. The preheated liposomes are incubated with doxorubicin hydrochloride (DOX:lipid weight ratio of 1:10); with respect to the amount of original total lipid used for the liposome preparation at $60^{\circ} \mathrm{C}$ for $1 \mathrm{~h}$. Unencapsulated DOX is removed by passing the liposome through a Sephadex-G50 (fine) column at a flow rate of $0.5 \mathrm{ml} / \mathrm{min}$ with HEPES buffered saline (10 $\mathrm{mM}$ HEPES $\mathrm{pH}$ 7.4 and $140 \mathrm{mM} \mathrm{NaCl}$ ) as the eluent. The resulting liposomes (MPTLDOX) are stored at $4^{\circ} \mathrm{C}$ until further use.

The DOX concentration of the liposomes is determined by a Cary Eclipse spectro-fluorimeter equipped with ThermoScan Software (Varian, Palo Alto, CA) at $485 \mathrm{~nm}$ excitation and $590 \mathrm{~nm}$ emission wavelength. $20 \mu \mathrm{l}$ DOX loaded liposomes are incubated in $1 \mathrm{ml}$ HEPES buffered saline for up to $60 \mathrm{~min}$ and the fluorescence intensity is measured after various incubation times. Before measurement, the samples are allowed to cool down to room temperature. For quantification, a calibration curve is obtained with a dilution series of free doxorubicin in $1 \%$ Triton X-100 in HEPES buffered saline is used. Using the following formula, entrapment efficiency $(\%)=($ encapsulated drug in liposomes / amount of total drug) $\times 100 \%$ [24].

\section{Cells and cell culture}

The MCF-7 breast cancer cells are cultivated in RPMI 1640 medium supplemented with $10 \% \mathrm{FBS}$ and maintained at $37^{\circ} \mathrm{C}$ in a $5 \%$ $\mathrm{CO}_{2}$ incubator.

\section{Cytotoxicity study}

Cytotoxicity studies are done using MTT (3-(4,5-dimethylthiazol2-yl)-2,5-diphenyltetrazolium bromide) tetrazolium reduction assay. As suggested by Kulshrestha et al. [25] $1 \times 10^{4}$ cells per well are cultivated in 96-well plates overnight. The control group is untreated cells and the first MCF-7 treatment groups are: with magnetoplasmonic nanoshells only, with MPTL (at a lipid concentration of $10 \mathrm{mM}$ ) only, with laser irradiation only. For the control (untreated) group, the cells are washed with PBS, after that the fresh cell culture media is placed in an incubator for the next $24 \mathrm{~h}$. For the MPNS and MPTL treatments, the cells are cultured in $200 \mu \mathrm{l}$ medium containing nanoshells and MPTL (at lipid concentration of $10 \mathrm{mM}$ ), respectively. In order to study the effect of magnetic fields on nanoliposomes, during the first hour of incubation, the culture plates are positioned on the 96-well format magnetic plate (Chemicell-Germany) with a field gradient of 50-130 T/m. After 75 min, the cells are washed with PBS and incubated for another $24 \mathrm{~h}$ with fresh medium.

The second treatment groups are: laser hyperthermia mediated by MPTL only, MPTL with magnetic field (MF), MPTL-DOX only and MPTL-DOX with MF all at lipid concentration of $10 \mathrm{mM}$. In vitro hyperthermia of MCF-7 cells consisting of liposomes containing magneto-plasmonic nanoshells is done using Argon laser (Melles Griot /43 Series Ion Laser-USA) at $350 \mathrm{~mW}$ for 5 minutes with or without DOX. The thermometer is connected at the other end to a Windowsbased laptop where the results are displayed on the screen. During the experiment the temperature is maintained at $37 \pm 0.4^{\circ} \mathrm{C}$ recorded by a digital thermometer (Model No. HP-34420A). 
Citation: Khosroshahi ME, Ghazanfari L, Hassannejad Z, Lenhert S (2015) In-vitro Application of Doxorubicin Loaded Magnetoplasmonic Thermosensitive Liposomes for Laser Hyperthermia and Chemotherapy of Breast Cancer. J Nanomed Nanotechnol 6: 298. doi:10.4172/21577439.1000298

Page 3 of 9

\section{In vitro evaluation of thermo-chemotherapy}

In vitro evaluation of cellular uptake is based on 15 min incubation of cells in a solution containing $\mathrm{Ca}^{2+}$ ions and annexin V-FITC (at a final concentration of $1 \mu \mathrm{g} / \mathrm{ml}$ ). The annexin $\mathrm{V}$-binding buffer consists of $10 \mathrm{mM}$ HEPES-NaOH, pH 7.4, $150 \mathrm{mM} \mathrm{NaCl}, 5 \mathrm{mM} \mathrm{KCl}, 1 \mathrm{mM}$ $\mathrm{MgCl}_{2}$, and $1.8 \mathrm{mM} \mathrm{CaCl}_{2}$. The stained cells are mounted on slides and immediately visualized under the fluorescence microscope. A two steps procedure of preparation and application of the multihybrid nanoliposomes is illustrated in Figure 1.

\section{Characterization}

Transmission electron microscopy (TEM) as performed using a CM 200 FEG STEM Philips-M.E.R.C operating at the voltage of 200 $\mathrm{kV}$. Liposomes are observed by TEM following negative staining with uranyl acetate. Liposomes are diluted with distilled water and dropped on a PDL-coated copper grid. The excessive sample is removed with filter paper and air-dried for $1 \mathrm{~min}$ at room temperature. Subsequently, uranyl acetate solution $(10 \mu \mathrm{l}$ of $1 \%)$ is dropped onto the grid. After 1 min the excess staining solution is removed with filter paper and is allowed to dry in the air before introduction into the microscope. Fourier Transform Infrared Spectroscopy (FT-IR) spectra are recorded by TENSOR27 FT-IR spectrometer. The obtained nanoparticles are dried, mixed with $\mathrm{KBr}$ and compressed into a pellet. UV-VIS spectroscopy of nanoparticle suspensions is taken on a CARY100 UV-

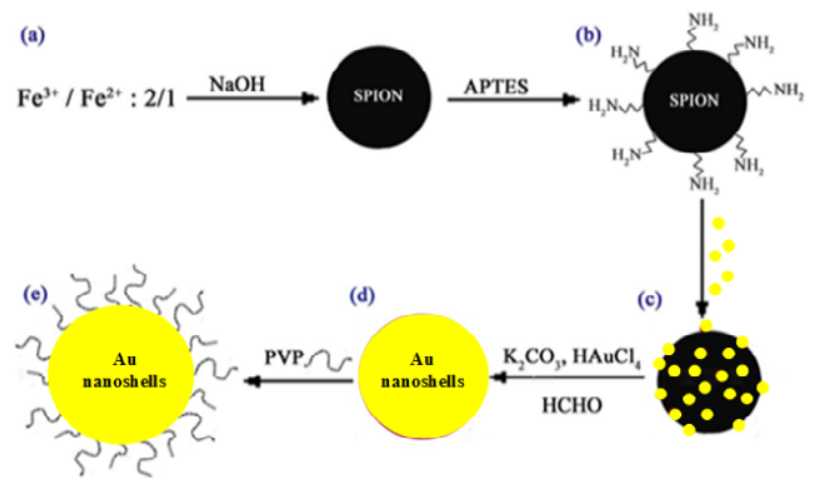

(f)

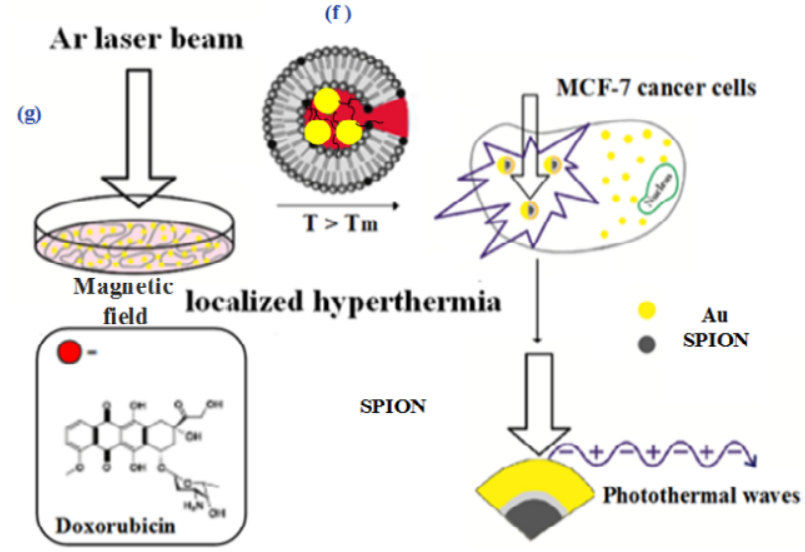

Figure 1: A two steps procedure of preparation and application of the nanoliposomes. (a) synthesis of SPION, (b) functionalization of SPION with APTES, (c) colloidal gold attachment to the amine groups, (d) gold nanoshell growth, (e) PVP coating on the surface of gold nanoshell, (f) magnetoplasmonic nanoshells and Dox co-loaded liposome, and $(\mathrm{g})$ in-vitro experiment.
VIS spectrophotometer with a $10 \mathrm{~mm}$ optical path length quartz cuvette. The mean hydrodynamic radius and polydispersity of the liposomal vesicles are determined using Dynamic Laser Light Scattering (DLS). The scattered laser light intensity at $90^{\circ}$ is measured by light scattering photometer using a wavelength of $488 \mathrm{~nm}$ (Brookhaven instrument Corporation, USA). Stability of magnetoliposomes formulation is evaluated by measuring the zeta potential. The zeta potential is measured as the particle electrophoretic mobility of charged, colloidal suspensions by means of laser microelectrophoresis in a thermostatted cell at room temperature (Brookhaven Instruments Corporation, USA). Every sample measurement is repeated 5 times. Encapsulation efficiency of gold nanoshells within the liposomes is determined by inductively coupled plasma mass spectrometry (ICP-MS). Samples for ICP-MS (VARIAN 735-ES) analysis are frozen, lyophilized, and dissolved in nitric acid hydrochloride, prepared by adding nitric acid $(100 \mu \mathrm{L})$ and hydrochloric acid $(300 \mu \mathrm{L}$ of $37 \%)$ for $72 \mathrm{~h}$ to dissolve particles. Then, samples are diluted to $2 \mathrm{~mL}$ with $\mathrm{HNO}_{3}(1.6 \mathrm{~mL}$ of $2 \%$ ) and analyzed via ICP-MS against standards. Magnetization measurements are carried at $300 \mathrm{~K}$ in a magnetic field $(\mathrm{H})$ of up to $20 \mathrm{kOe}$ with a vibrating sample magnetometer (Meghnatis Daghigh Kavir Co. VSM/AGFM) that can measure magnetic moments as low as $10^{-3} \mathrm{emu}$. For the magnetization measurements, NPs are in dry powder form obtained by evaporating the water from the solution. The samples are dried by freeze dryer (Pishtaz Engineering Co. Model: FD-4).

\section{Statistical analysis}

All experiments are performed at least in triplicate. The value of particle size determined by TEM micrographs is the average of at least 50 measurements and reported as mean \pm standard deviation. The SPSS 15.0 as used to perform the calculations. Paired-sample t-test is used to compare the difference between the control and treated groups. $P$ values of $<0.05$ are considered statistically significant.

\section{Results and Discussion}

\section{FTIR}

Figure 2 shows the FT-IR spectra of bare SPION (a), aminefunctionalized SPION (b), PVP (c) and PVP-covered gold nanoshell (d). The broad band at region of $3550-3200 \mathrm{~cm}^{-1}$ with moderate intensity is assigned to the presence of $-\mathrm{OH}$ groups at the surface of nanoparticles. The peaks at 444 and $579 \mathrm{~cm}^{-1}$. In Figure 2(a) are assigned to the vibration of $\mathrm{Fe}-\mathrm{O}$ bond, which are characteristic bands of magnetite. The broad band at $1623 \mathrm{~cm}^{-1}$ and the split band at 3414 $\mathrm{cm}^{-1}$ can be attributed to the $\mathrm{N}-\mathrm{H}$ stretching vibration and $\mathrm{NH}_{2}$ bending mode of free $\mathrm{NH}_{2}$ groups, respectively. Also, it can be seen that the characteristic bands of the $\mathrm{Fe}-\mathrm{O}$ bond of amine-functionalized SPIONs shift to higher frequencies of 620 and $477 \mathrm{~cm}^{-1}$ compared with that of bare SPIONs (at 579 and $444 \mathrm{~cm}^{-1}$ ). These shifts have been attributed to the replacement of $-\mathrm{H}$ at the $\mathrm{Fe}-\mathrm{O}-\mathrm{H}$ groups on the surface of SPION by the more electronegative group of $-\mathrm{Si}\left(\mathrm{O}_{-}\right)_{2}-$ which results in the enhancement of bond force constant for Fe-O bonds. The FT-IR spectrum of PVP (Figure 2c) mainly consists of two bands at 1282 and $1664 \mathrm{~cm}^{-1}$ corresponding to the vibration of C-N and carbonyl group in pyrrolidone ring. Similar bands are also seen in the FT-IR spectrum of PVP-coated gold nanoshells. However, comparing with the spectrum of PVP, the resonance peak of C-N, at $1282 \mathrm{~cm}^{-1}$, was shifted to 1475 $\mathrm{cm}^{-1}$ and the band of $\mathrm{C}=\mathrm{O}$, at $1664 \mathrm{~cm}^{-1}$, red shifted to $1647 \mathrm{~cm}^{-1}$. The change of the spectrum indicates that the absorption of PVP on the gold shell is not on the basis of electrostatic attraction but gold atoms on the surface of nanoparticles would coordinate with $\mathrm{N}$ and $\mathrm{O}$ atoms 
Citation: Khosroshahi ME, Ghazanfari L, Hassannejad Z, Lenhert S (2015) In-vitro Application of Doxorubicin Loaded Magnetoplasmonic Thermosensitive Liposomes for Laser Hyperthermia and Chemotherapy of Breast Cancer. J Nanomed Nanotechnol 6: 298. doi:10.4172/21577439.1000298

Page 4 of 9

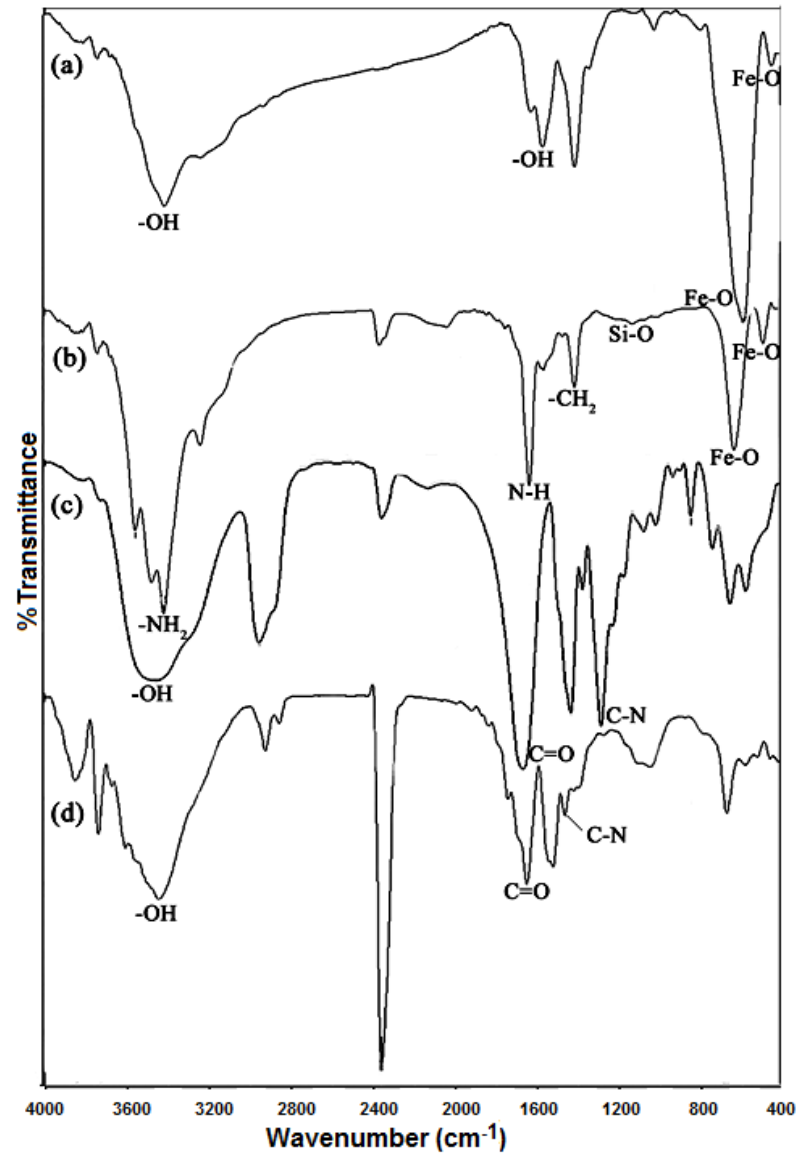

Figure 2: FT-IR spectra of bare SPION (a), amine-functionalized SPION (b), PVP (c) and PVP- covered SPION/gold nanoshells (d).

of PVP which is consistent with previously reported results [26]. FTIR confirms the presence of a PVP coating on the nanoshells.

\section{DLS}

The effect of surface coating on the stability of SPIONs is observable from DLS data. The volume-weighted hydrodynamic size measured by DLS for nanostructures are summarized in Table 1. The reduced hydrodynamic size of amine-functionalized SPIONs shows more stability of nanoparticle suspension after silanization reaction. This effect can be also seen after coating of the amine-functionalized SPIONs with a continuous thin layer of gold, which reduced the hydrodynamic size of gold nanoshells to $57 \mathrm{~nm}$. After PVP coating of gold nanoshells the hydrodynamic size increased to $102 \mathrm{~nm}$ which is because the nanoshell's surface functionalization with long chain PVP molecules. This result agrees well with the previously reported thickness in the case of PVP adsorbed on palladium nanoparticles [27]. The hydrodynamic diameter of the MPTL-DOX is $240 \mathrm{~nm}$. The size distribution of this formulation is quite homogenous as polydispersity index is around 0.19 .

\section{VSM}

Figure 3 shows the magnetization curve for magnetite core and gold nanoshells at ambient temperature. It indicates the superparamagnetic behaviour of nanostructures. It can be deduced that the magnetite NPs have magnetization saturation (Ms) of about $46.94 \mathrm{emu} / \mathrm{g}$. Absence of hysteresis loss with zero coercivity in the magnetization curve suggests the superparamagnetic nature of the particles. The Ms value of the resultant gold nanoshells decreases to $11.98 \mathrm{emu} / \mathrm{g}$, when the gold is added. With the same magnetite core size and gold shell thickness of $3.5 \mathrm{~nm}$, the Ms value for the synthesized nanoshells in this paper is larger than that reported by $\mathrm{Xu}$ et al. [28].

\section{TEM}

The physical size of particles at different steps of nanoshell fabrication is determined by bright field TEM. Based on TEM micrographs (Figure 4), the average diameter of SPIONs and SPION/ gold nanoshells are $9.5 \pm 1.4$ and $15.8 \pm 3.5 \mathrm{~nm}$, respectively. TEM image confirms the formation of magnetoplasmonic liposome (Figure 5). The clear margin of each encapsulated nanoparticle indicates the steric hindrance of PVP-covered nanoshells. Based on TEM micrographs, the average diameter of SPION/gold nanoshells are $15.8 \pm 3.5 \mathrm{~nm}$. It is observed that MPNS are packed within the liposomes. The thickness of the lipid bilayer membrane surrounding the collection of nanoshells is $6.5 \pm 1.6 \mathrm{~nm}$ measured by NIH Image J software (http://rsb.info.nih. gov/ij/), suggesting the formation of unilamellar liposomal structure. A value of 7-8 $\mathrm{nm}$ is also reported for lipid bilayer membrane [29].

\section{Encapsulation efficiency of nanoshells}

A magnetoplasmonic nanoshells (MPNS) encapsulation efficiency of $54 \%$ is obtained. Higher encapsulation of MPNS results in higher heating ability, therefore it increases the toxicity of the liposomes. In this aspect, this magnetoplasmonic liposomes is superior to the others reported in literature [22]. The concentration of nanoshells has

\begin{tabular}{|l|c|c|c|}
\hline & $\begin{array}{c}\text { TEM size }=\mathbf{S E} \\
\mathbf{( n m )}\end{array}$ & $\begin{array}{c}\text { DLS volume- } \\
\text { weighted } \\
\text { size (PDI) } \mathbf{( n m})\end{array}$ & $\begin{array}{c}\text { Electrophoretic } \\
\text { potential } \mathbf{\pm} \text { SE } \\
\mathbf{( m V}\end{array}$ \\
\hline SPION & $9.5 \pm 1.4$ & $201(0.22)$ & $-29 \pm 0.6$ \\
\hline $\begin{array}{l}\text { SPION/Au } \\
\text { nanoshell }\end{array}$ & - & $57(0.21)$ & $-21 \pm 0.9$ \\
\hline $\begin{array}{l}\text { PVP-coated } \\
\text { nanoshell (MPNS) }\end{array}$ & $15.8 \pm 3.5$ & $102(0.22)$ & $-30 \pm 0.7$ \\
\hline MPTL & $97.5 \pm 5.7$ & $142(0.20)$ & $-40 \pm 0.8$ \\
\hline MPTL-DOX & & $240(0.19)$ & $-39 \pm 0.6$ \\
\hline
\end{tabular}

Table 1: Properties of synthesized nanoparticles in different steps of fabrication.

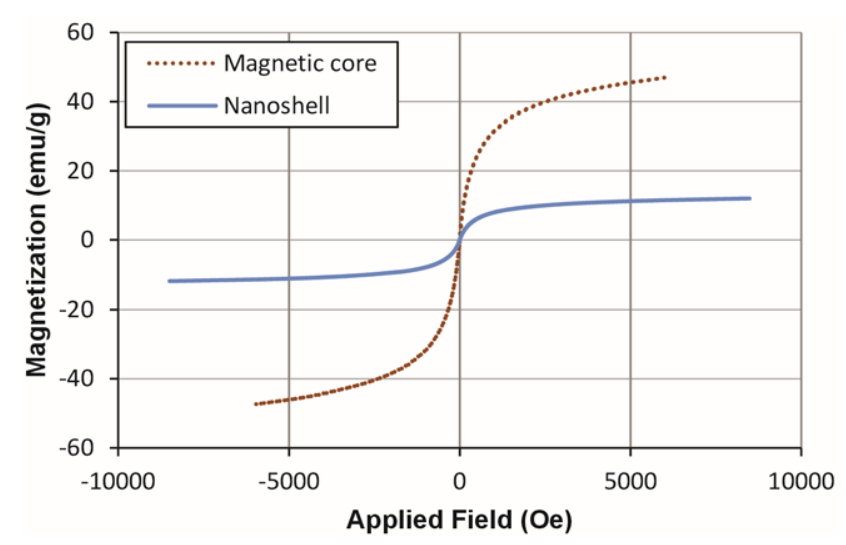

Figure 3: (a) Variation of magnetization with applied magnetic field for bare magnetite core and magntoplasmonic nanoshells. 
Citation: Khosroshahi ME, Ghazanfari L, Hassannejad Z, Lenhert S (2015) In-vitro Application of Doxorubicin Loaded Magnetoplasmonic Thermosensitive Liposomes for Laser Hyperthermia and Chemotherapy of Breast Cancer. J Nanomed Nanotechnol 6: 298. doi:10.4172/21577439.1000298

Page 5 of 9
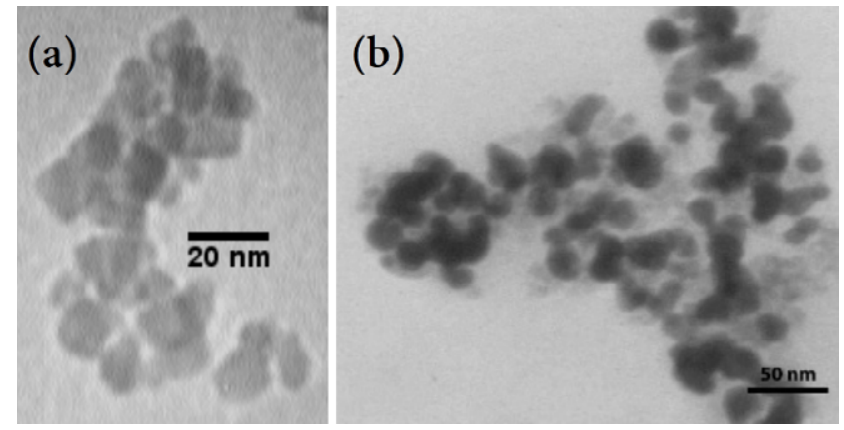

Figure 4: TEM images showing (A) SPIONs of diameter $9.5 \pm 1.4 \mathrm{~nm}$ and $(\mathrm{B})$ SPION/gold nanoshells.

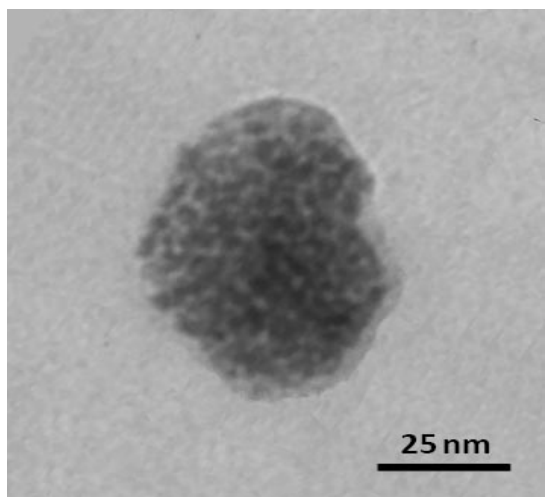

Figure 5: TEM image of gold nanoshell-encapsulated liposome.

a significant effect on the amount of heat generated at a given power density. This effectively indicates that not only do the MPNSs play an important role in generating thermal effect, but also an enhanced absorption cross section for spherical metal nanoshells can be achieved at optimized value of concentration for a better laser-hyperthermia [16]. The absorption efficiency of our synthesized MPNS corresponds to $0.656 \mathrm{at}_{\mathrm{SPR}}$ of $531 \mathrm{~nm}$. Maximum value of the parameter DT/I shows the efficiency of transformation of absorbed optical energy by MPNS into the thermal energy, where $\mathrm{T}$ is the temperature and $\mathrm{I}$ is constant intensity of laser radiation during pulse duration. In our case, the nanoshell efficiency parameter equals $2 \times 10^{-5}{ }^{\circ} \mathrm{C} \mathrm{cm} / \mathrm{W}$.

Furthermore, an experiment was set up to measure the temperature of the aqueous medium containing dispersed gold nanoshells and magnetoplasmonic liposomes where the the cuvette containing the sample was irradiated by laser at $17 \mathrm{~W} / \mathrm{cm}^{2}$ for $400 \mathrm{~s}$. A thermistor probe (Redfish Sensors Inc., Model QTGB-14 D3) with an accuracy of $0.15 \%$ was placed in the solution to monitor the temperature change where it was recorded by a thermometer (Model No. HP-34420A. The output of the thermometer was connected to a Windows-based laptop where the results were displayed. As it is shown in Figure 6, at low concentrations, the temperature of MPNS increases steadily and linearly up to $4^{\circ} \mathrm{C}$ in about $300 \mathrm{~s}$ where it reaches the turning point and saturates after 400 s. At $100 \mu \mathrm{g} / \mathrm{ml}$ the temperature reaches its maximum of $6.5^{\circ} \mathrm{C}$ but when the concentration was increased to $300 \mu \mathrm{g} / \mathrm{ml}$, the temperatures increases linearly up to $8^{\circ} \mathrm{C}$ in about $120 \mathrm{~s}$ where it shows a turning point and at this stage the temperature rise gradually until it is maximized at $12^{\circ} \mathrm{C}$ after $400 \mathrm{~s}$. Such a phenomenon can be due to the arrangement, density, and potential for aggregation of Au nanoshells. Therefore, it results in a stronger surface plasmon absorption of light and more efficient photothermal effects. All the experiments demonstrate that the temperature increases with increasing MPNs concentration and the exposure time. However, in the case of MPNS encapsulated liposomes, Figure 7, the maximum temperature obtained was about $6^{\circ} \mathrm{C}$ after 400 $\mathrm{s}$ which as expected is less than the case of without liposome. These results clearly confirm that the fabricated MNSs not only are suitable candidates for hyperthermia tumor therapy but even with liposome carriers the temperature increase is sufficient to cause the hyperthermic effect about $42-45^{\circ} \mathrm{C}$. The question that how fast and what temperature is generally achievable, entirely depends on the MPNS concentration, the laser power and the irradiation time.

\section{Laser induced fluorescence spectroscopy (LIF)}

The fluorescence response of Dox was studied at room temperature using $488 \mathrm{~nm}$ wavelength of argon laser which is close to its excitation wavelength. The emission spectrum was recorded and processed by Spectrasuit software. The results of LIF experiment for Dox, TL, TLDox, and MPTL-Dox are shown in Figure 8 where a peak at $590 \mathrm{~nm}$ corresponding to Dox emission is observesd. A small bump at $550 \mathrm{~nm}$ is thought to be due to Au nanoshell response.

Recent studies have indicated that AuNPs act as good quenchers

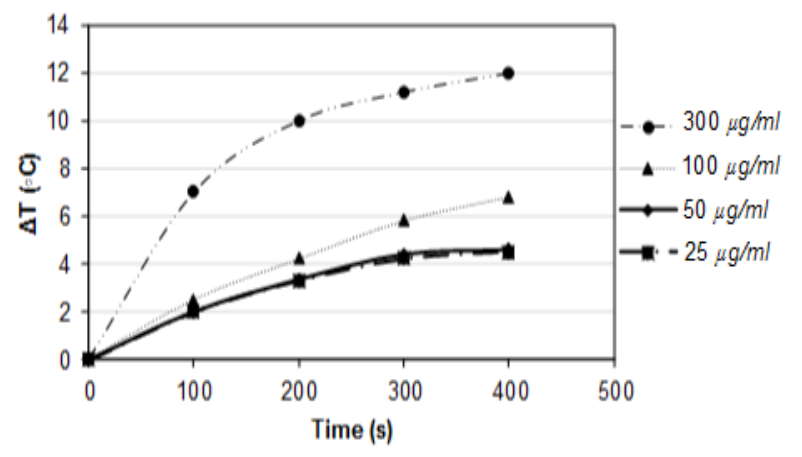

Figure 6: Temperature variation $(\Delta T)$ of MPNSs at different concentrations with irradiation time at $17 \mathrm{~W} / \mathrm{cm}^{-2}$.

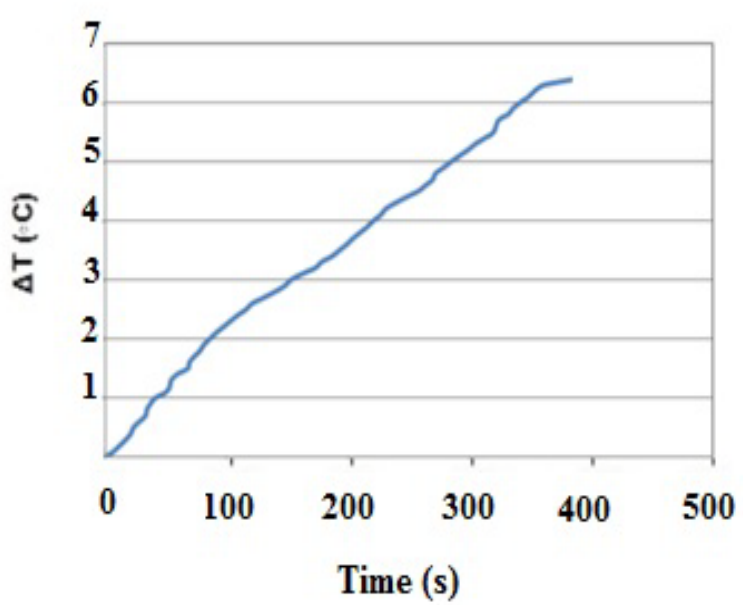

Figure 7: Temperature variation $(\Delta T)$ of MPNS encapsulated liposomes at $100 \mu \mathrm{g} / \mathrm{ml}$ with irradiation time. 
Citation: Khosroshahi ME, Ghazanfari L, Hassannejad Z, Lenhert S (2015) In-vitro Application of Doxorubicin Loaded Magnetoplasmonic Thermosensitive Liposomes for Laser Hyperthermia and Chemotherapy of Breast Cancer. J Nanomed Nanotechnol 6: 298. doi:10.4172/21577439.1000298

Page 6 of 9

of many fluorescence donors, due to the nanosurface energy transfer (NSET) effect [30]. Addition of gold nanoshells to TL-Dox result in a significant quenching of doxorubicin fluorescence (Figure 8d), demonstrating the presence of NSET between the doxorubicinyl groups and Au nanoshells.

\section{Encapsulation efficiency of DOX and drug release study under laser irradiation}

The drug encapsulation efficiency of $95 \%$ for DOX-loaded magnetoplasmonic liposome is calculated. The liposome formulation DPPC:cholesterol:DSPE-PEG2000 shows DOX release of less than 5\% at $37^{\circ} \mathrm{C}$ following $24 \mathrm{~h}$ incubation. This particular lipid composition has $\mathrm{T}_{\mathrm{m}}$ at around $41.3^{\circ} \mathrm{C}$ [22], as a thermosensitive formulation, so minimal leakage at $37^{\circ} \mathrm{C}$ and triggered DOX release at $43^{\circ} \mathrm{C}$ is expected. DOX release from magnetoplasmonic liposomes are $65 \%$ and $100 \%$ in 50\% FBS following 5 min Argon ion laser $(350 \mathrm{~mW}, \mathrm{l}=514 \mathrm{~nm})$ irradiation and $24 \mathrm{~h}$ incubation at $37^{\circ} \mathrm{C}$, respectively. Laser induced hyperthermia raises the temperature from $37^{\circ} \mathrm{C}$ to $43^{\circ} \mathrm{C}$ which leads to the phase transition of the lipid combination causing massive release of the encapsulated drug. Most of the magnetic liposomes reported in earlier studies $[4,31]$ have been composed of DPPC alone, which shows a high burst of drug release even at $37^{\circ} \mathrm{C}$. By adding saturated lipids, the compressibility moduli of the liposome could be increased.

Furthermore, it has been established that drug release from low temperature sensitive liposomes occurs via grain boundary permeabilization when it is heated into the region of its phase transition temperature [5]. However, the grain boundary structures of the bilayer could bind proteins that are responsible for opsonization. Therefore, in order to reduce the toxicity (by avoiding the opsonization) a few mol\% of DSPE-PEG2000 is added to cover the bilayer [5].

\section{Drug release from thermosensitive liposomes}

As reported by Pradhan et al., [22], phase transition temperature of the liposome prepared with formulation of DPPC:CHOL:DSPEPEG2000 at the molar ratio of $80: 20: 5$ is $\sim 42^{\circ} \mathrm{C}$. In this report, the drug release rate from similar lipid composition is measured as a function of time at $43^{\circ} \mathrm{C}$. The release rate of thermosensitive liposome varies according to the composition of liposome, its preparation procedure, and heating temperature [32]. The relation between percentage release and exposure time is found to follow the first-order kinetics expressed as [33]

$$
\% R(t)=R_{c}\left(1-e^{-\mathrm{k}_{\mathrm{rel}}^{\mathrm{t}}}\right)
$$

where $\% \mathrm{R}(\mathrm{t})$ is the percentage of drug released at exposure time $t, \mathrm{k}_{\mathrm{rel}}$ is liposome release rate and $R_{c}$ is the total percentage of drug released at a given heating temperature. It is assumed that at $t=0$ the temperature is $37^{\circ} \mathrm{C}$. This equation is used to fit the experimental data obtained at $43^{\circ} \mathrm{C}$ [32]. From the best fitting curve (shown in Figure 9) obtained by using nonlinear least squares method, the release rate is found to be 0.07 for TLDox and 0.09 for MPTL-Dox. In addition, doxorubicin release from both of the formulations are assessed (Table 2).

\section{Cytotoxicity study}

Figure 10 shows the cytotoxic effect of laser, MPNS, and MPTL on MCF-7 cells. The untreated (control) and first treated (i.e. exposure of untreated cells to laser, MPNS, or and MPTL) groups are non-toxic. After being heated, the cells develop resistance to heat, which reduces the likelihood of being destroyed by direct thermal cytotoxic effects. Because Hyperthermia alters the cell walls by means of so-called heat shock proteins, cancer cells then react much more effectively to the radiation [34]. So before the laser hyperthermia experiment, the cells are normally preheated which in our case it was done by using a
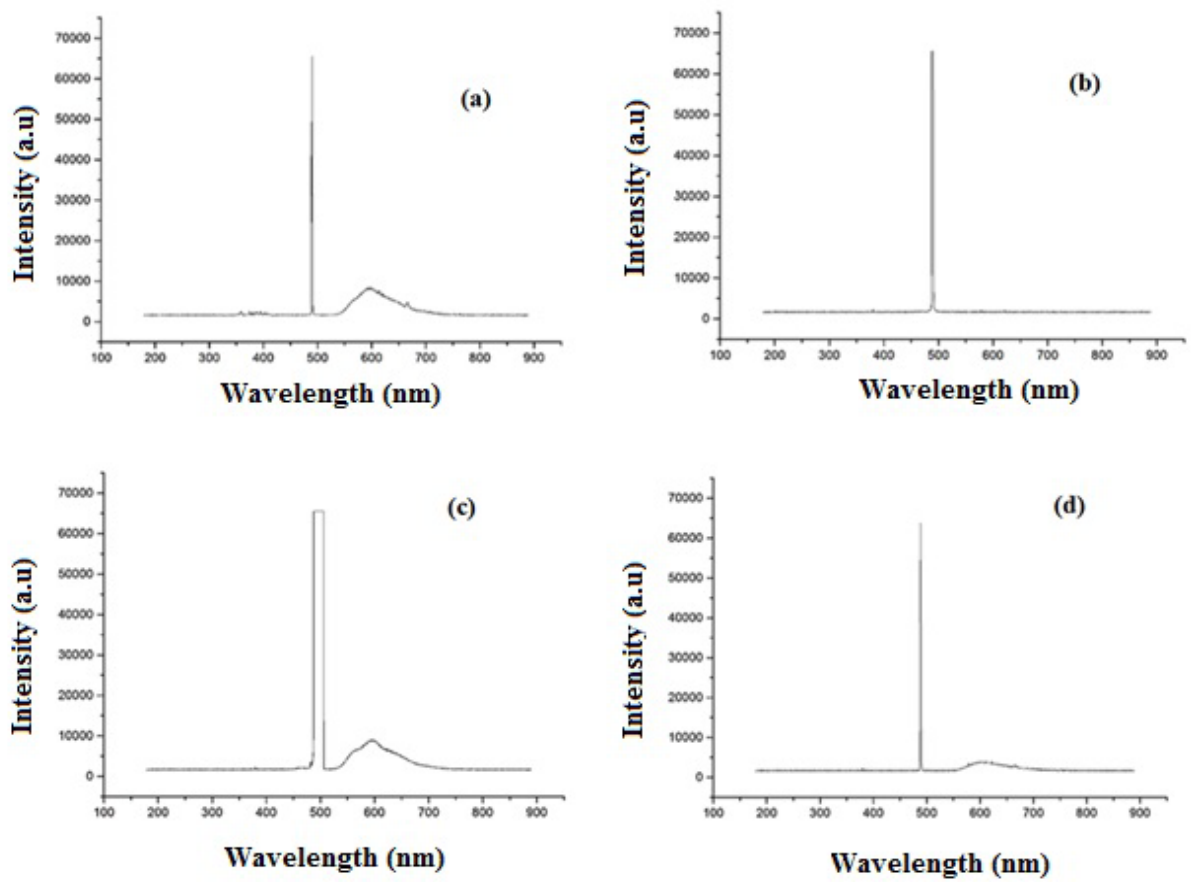

Figure 8: LIF spectra (a) free Dox, (b) liposomes, (c) Dox loaded liposomes, (c) Dox and gold nanoshells co-loaded liposomes. 
Citation: Khosroshahi ME, Ghazanfari L, Hassannejad Z, Lenhert S (2015) In-vitro Application of Doxorubicin Loaded Magnetoplasmonic Thermosensitive Liposomes for Laser Hyperthermia and Chemotherapy of Breast Cancer. J Nanomed Nanotechnol 6: 298. doi:10.4172/21577439.1000298

Page 7 of 9

(a)

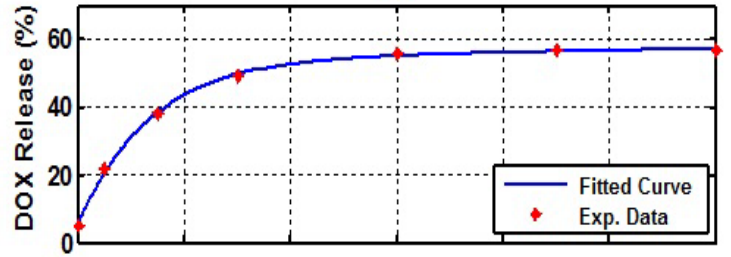

(b)

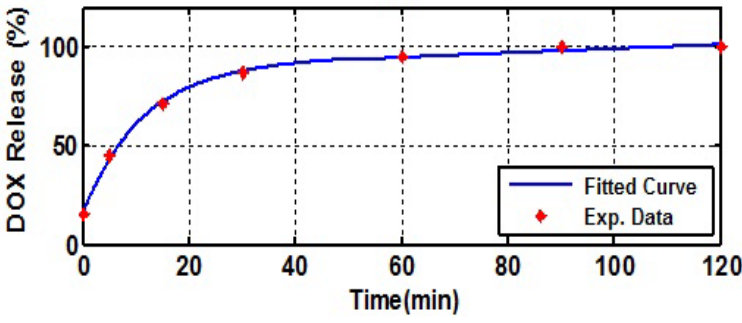

Figure 9: Rate of nanoliposomes drug release (a) TL-Dox, (b) MPTL-Dox with drug concentration of $0.13 \mu \mathrm{g} / \mathrm{ml}$ at $43^{\circ} \mathrm{C}$.

\begin{tabular}{|c|c|c|c|}
\hline Sample & $\mathbf{2 4 \mathbf { h r }}-\mathbf{3 7}^{\mathbf{}} \mathbf{C}$ & $\mathbf{5 m i n}$ Ar Laser Irradiation & $\mathbf{2 4 h r}^{-37^{\circ} \mathbf{C}}$ \\
\hline TI-DOX & $5 \%$ & $12 \%$ & $69 \%$ \\
\hline MPTL-DOX & $15 \%$ & $65 \%$ & $100 \%$ \\
\hline
\end{tabular}

Table 2: Doxorubicin release from thermosensitive liposomes irradiated with $\mathrm{Ar}$ ion laser $(350 \mathrm{~mW})$.

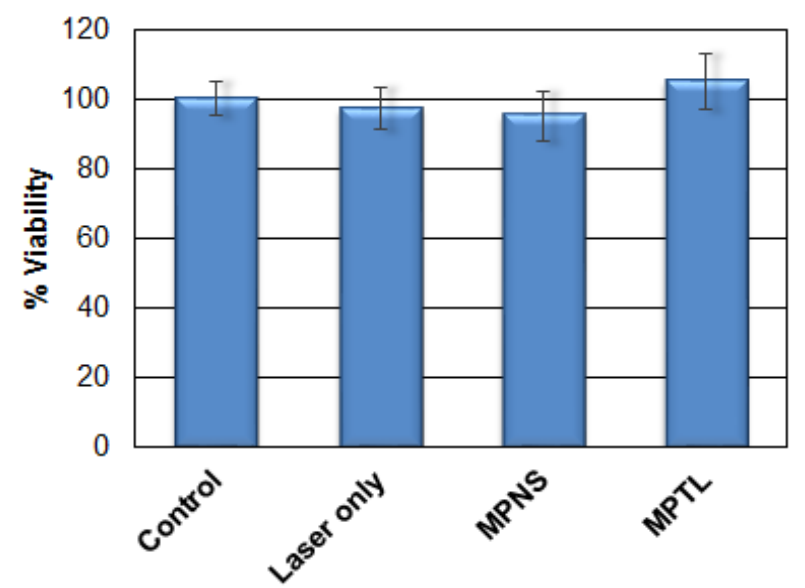

Figure 10: Cytotoxicity profile of control (untreated) and first treated (exposure of untreated cells to laser, MPNS, and MPTL) groups (mean \pm SD; $n=3, P>0.05)$

water bath (Lab Companion, USA). The heating effect of surrounding liquid medium on viability of MCF-7 and L-929 cells was assessed after being heated for $5 \mathrm{~min}$ at the temperature of $43^{\circ} \mathrm{C}$. The cell viability is significantly ( \%50) decreasing in L-929 cells, but as for MCF-7 cells, there is no significant difference between control and treated cells. The cytotoxic effects of laser hyperthermia and chemotherapy using the prepared formulation as single and combined modalities are illustrated in Figure 11. Data are presented as a percentage of the cell viability where viability of control group is taken as $100 \%$.

Magnetic guidance is one of the strategies for the accumulation of nanoparticles. Therefore, when the magnetic field is applied, most of the MNS are accumulated at the bottom of the wells, where the cells are present. After that, based on the SPR absorption in gold nanoshells, an energy relaxation is followed through a non-radiative decay channels which results in an increase in kinetic energy, leading to overheating of the local environment around the light-absorbing species. Clearly, the hyperthermia effects are expected to be higher, where the applied magnetic field has accumulated of most of the nanoparticles around the cells. Because it increases the possibility of Au NPs aggregation, hence resulting in a stronger localized SPR and thus more efficient photothermal effects. Moreover, the combined laser hyperthermia treatment and magnetically targeting MPTL-DOX, at doxorubicin concentration of $0.5 \mu \mathrm{g} / \mathrm{ml}$ (IC-50 of MCF-7 cells) [35] and $0.1 \mu \mathrm{g} /$ $\mathrm{ml}$ result in less than $1 \%$ and less than $15 \%$ cell viability (Figure 11), respectively. An analysis of these combined treatments using Valeriote's formula [36] shows that the magnetically targeted MPTLDOX and laser hyperthermia treatments are synergistic in nature.

\section{Fluorescence microscopy}

Figure 12 shows that the internalized nanoliposomes release doxorubicin in the acidic organelles of MCF-7 cells, which would activate the fluorescence of doxorubicin quenched by Au nanoshells due to NSET. The fluorescence microscopy images of MPTL-DOX in MCF-7 cells obtained by a fluorescence microscope Eclipse 80i (Nikon, Japan). DOX-MPNS loaded liposomes are incubated with MCF-7 cells for about $75 \mathrm{~min}$ (with and w/o MF) and irradiated with Ar laser at $37^{\circ} \mathrm{C}$. The image (a) shows the red fluorescence in the area or the nucleus of the MF applied to MPTL-DOX in MCF-7 cells. The nucleus of the cells in MPTL-DOX-w/o MF (d) does not show this fluorescence. This confirms that under magnetic field, the drug loaded NPs are internalized by the cells. It has been reported that chemosensitivity to DOX in MCF7 is due to the decreased level of DNA double-strand break repair proteins, Rad51 [37]. Aroui et al., have shown that the major mechanism of DOX activity is the inhibition of topoisomerase II and stabilization of a ternary drug-topoisomerase II (TOPO II)-DNA complex, causing DNA damage and induction of apoptosis [38]. Furthermore, Prasad et al., [39] have shown that hyperthermia causes apoptosis by irreversibly damaging the actin and tubulin structures of cells. Hyperthermia damages different cellular structures such as enzyme complexes required for DNA synthesis and

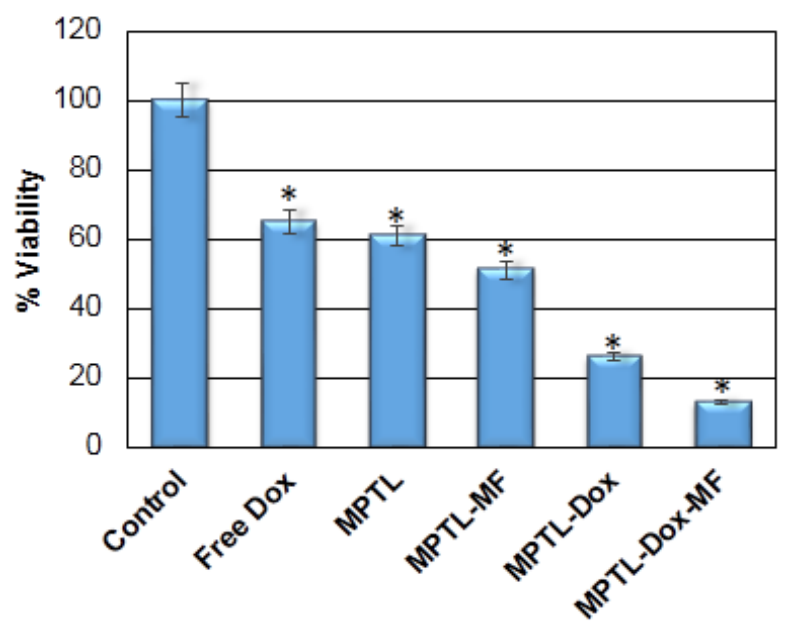

Figure 11: Cytotoxicity profile of the second treated group including lase irradiated MPTL and MPTL-DOX formulations on MCF-7 cells (mean \pm SD $n=3$, ${ }^{*} P<0.05$ ), where permanent magnetic field (MF) is applied during the incubation of some samples, as indicated. 
Citation: Khosroshahi ME, Ghazanfari L, Hassannejad Z, Lenhert S (2015) In-vitro Application of Doxorubicin Loaded Magnetoplasmonic Thermosensitive Liposomes for Laser Hyperthermia and Chemotherapy of Breast Cancer. J Nanomed Nanotechnol 6: 298. doi:10.4172/21577439.1000298
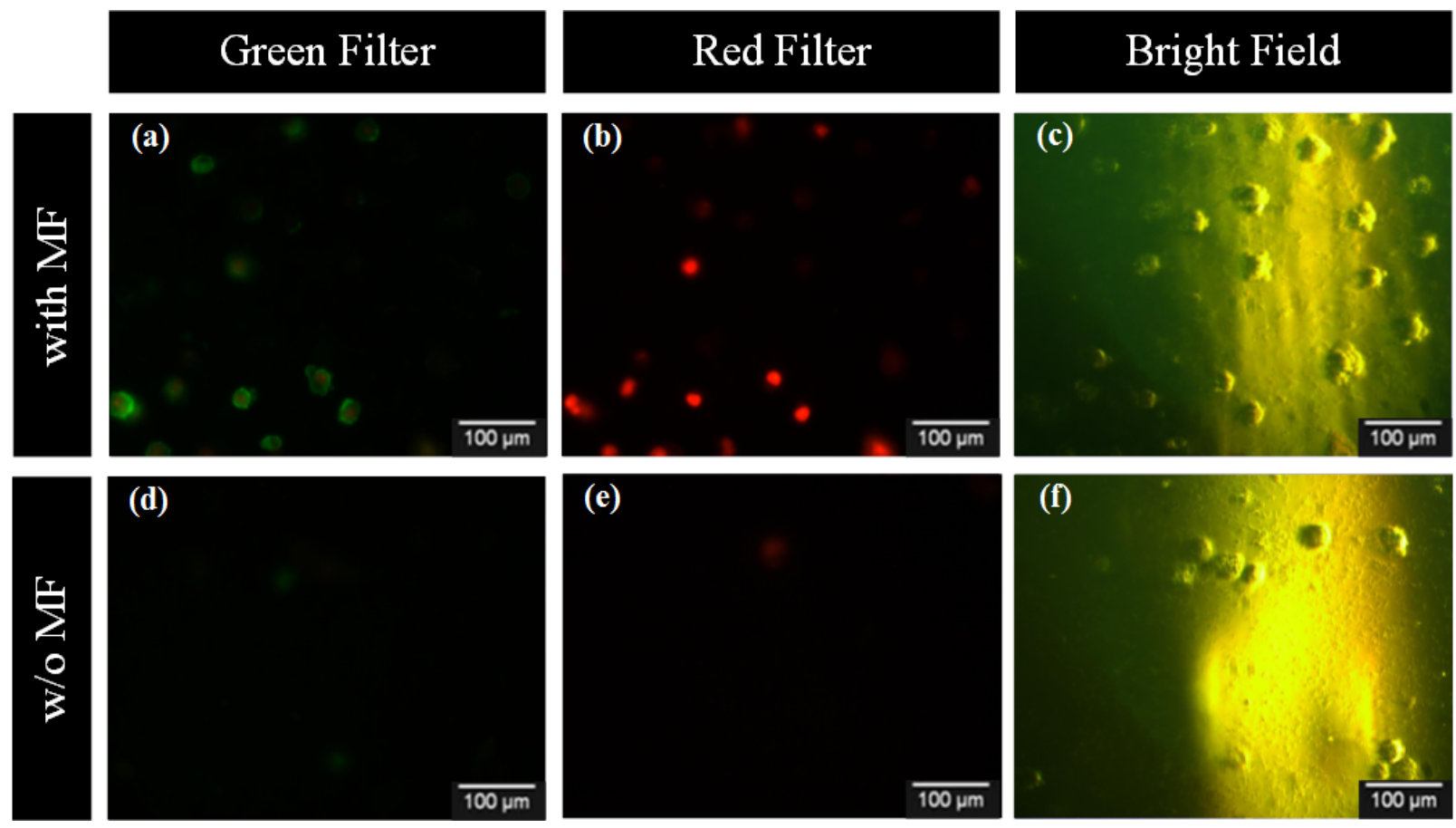

Figure 12: Uptake of doxorubicin loaded MPTL by MCF-7 cells, the cells are incubated with drug loaded nanostructures for about 75 min, a-c: with permanent magnetic field (MF), d-f: without (MF) and irradiated with $\mathrm{Ar}$ laser at $37^{\circ} \mathrm{C}$. The images are obtained by the fluorescence microscope equipped with green and red filters for, Annexin V-FITC and DOX respectively $(n=3)$.

repair [40]. We believe that the presence of gold nanoshells enhances the laser hyperthermia effect in a controlled manner.

In addition, apoptosis is a mode of cell death that is accompanied by specific alterations to the plasma membrane. In Figure 12, membrane blebbing can be identified which is characteristic of apoptotic cells [41]. Redistribution of phosphatidylserine from the inner to the outer plasma membrane leaflet has become one of the most widely used markers for apoptotic cells in mammals. This is largely due to the availability of annexin $\mathrm{V}$ probe, as a sensitive phosphatidylserine-binding protein. The FITC-conjugated annexin V-binding assay provides a very specific, rapid and reliable technique to detect apoptosis. Analysis of fluorescence microscopy images is conducted to reveal the enhanced cell apoptosis caused by the magnetoplasmonic nanoshells and doxorubicin under combined chemotherapeutic and hyperthermia therapies. Therefore, this experiment indicates the doxorubicin loading into the liposomes in addition to indicating the potential application of this hybrid nanosystem in fluorescence imaging.

\section{Conclusion}

In the present study, fabrication of a new class of doxorubicinloaded MPNS encapsulated thermosensitive liposomes is presented. The drug release behavior of the formulation after Ar laser irradiation and $24 \mathrm{~h}$ incubation at $37^{\circ} \mathrm{C}$ is studied. Moreover, the cytotoxic and apoptotic effects of combined laser hyperthermia and chemotherapy for MPTL-DOX are evaluated for MCF-7 cells. In our case, cytotoxicity and uptake of DOX are enhanced under magnetic field. We believe that preliminary studies suggest the potential application of MPTL-DOX as biomarker and for combined chemotherapy and laser hyperthermia. Further research is required for optimization of the effect of MPNSs size and laser wavelength for in-vivo higher penetration and thermal induction.

\section{References}

1. Puvvada NA (2011) Nanomedical platform for drug delivery. J Nanomed Nanotechnol 2:1-5.

2. Yiv SH, Uckun FM (2012) Lipid spheres as attractive nanoscale drug delivery platforms for cancer therapy. J Nanomed Nanotechnol 3: 1-6.

3. Gowda R, Jones NR, Banerjee S, Robertson GP (2013) Use of Nanotechnology to Develop Multi-Drug Inhibitors For Cancer Therapy. J Nanomed Nanotechnol 4.

4. Babincová M, Cicmanec P, Altanerová V, Altaner C, Babinec P (2002) ACmagnetic field controlled drug release from magnetoliposomes: design of a method for site-specific chemotherapy. Bioelectrochemistry 55: 17-19.

5. Landon CD, Park JY, Needham D, Dewhirst MW (2011) Nanoscale Drug Delivery and Hyperthermia: The Materials Design and Preclinical and Clinical Testing of Low Temperature-Sensitive Liposomes Used in Combination with Mild Hyperthermia in the Treatment of Local Cancer. Open Nanomed J 3: 38-64.

6. Tsalach A, Steinberg I, Gannot I (2014) Tumor localization using magnetic nanoparticle-induced acoustic signals. IEEE Trans Biomed Eng 61: 2313-2323.

7. Candido NM, Calmon MF, Taboga SR, Bonilha JL, dos Santos MC, et al. (2014) High efficacy in hyperthermia-associated with polyphosphate magnetic nanoparticles for oral cancer treatment. J Nanomed Nanotechol 3: 1-11

8. Hassannejad Z, Khosroshahi ME, Firouzi M (2014) Fabrication and characterization of magnetoplasmonic liposome carriers. Nanosci Technol 1: 1-9.

9. Syed A, Raja R, Kundu GC, Gambhir S, Ahmad A (2013) Extracellular biosynthesis of monodispersed gold nanoparticles, their characterization, cytotoxicity assay, biodistribution and conjugation with the anticancer drug doxorubicin. J Nanomed Nanotechol 4: 1-6.

10. Paasonen L, Sipilä T, Subrizi A, Laurinmäki P, Butcher SJ, et al. (2010) Goldembedded photosensitive liposomes for drug delivery: triggering mechanism and intracellular release. J Control Release 147: 136-143.

11. Lukianova-Hleb EY, Oginsky AO, Shenefelt DL, Drezek RA, Hafner JH, et 
Citation: Khosroshahi ME, Ghazanfari L, Hassannejad Z, Lenhert S (2015) In-vitro Application of Doxorubicin Loaded Magnetoplasmonic Thermosensitive Liposomes for Laser Hyperthermia and Chemotherapy of Breast Cancer. J Nanomed Nanotechnol 6: 298. doi:10.4172/21577439.1000298

al. (2011) Rainbow Plasmonic Nanobubbles: Synergistic Activation of Gold Nanoparticle Clusters. J Nanomed Nanotechnol 2: 1-8

12. Hassannejad Z, Khosroshahi ME (2013) Synthesis and evaluation of time dependent optical properties of plasmonic-magnetic nanoparticles. Opt Mater 35: 644-651.

13. Fenske DB, Cullis PR (2008) Liposomal nanomedicines. Expert Opin Drug Deliv 5: 25-44.

14. Yavlovich A, Smith B, Gupta K, Blumenthal R, Puri A (2010) Light-sensitive lipid-based nanoparticles for drug delivery: design principles and future considerations for biological applications. Mol Membr Biol 27: 364-381.

15. Khosroshahi ME, Ghazanfari L (2012) Physicochemical characterization of Fe3O4/SiO2/Au multilayer nanostructure. Mater Chem Phys 133: 55-62.

16. Ghazanfari L, Khosroshahi ME2 (2014) Simulation and experimental results of optical and thermal modeling of gold nanoshells. Mater Sci Eng C Mater Biol Appl 42: 185-191.

17. Kou G, Wang S, Cheng C, Gao J, Li B, et al. (2008) Development of SM51-conjugated ultrasmall superparamagnetic iron oxide nanoparticles for hepatoma detection. Biochem Biophys Res Commun 374: 192-197.

18. Khosroshahi ME, Ghazanfari L (2010) Preparation and characterization of silica coated iron-oxide bionanoparticles under N2 gas. Physica E 42: 1824-1829.

19. Khosroshahi ME, Ghazanfari L (2012) Comparison of magnetic and rheologica behavior of uncoated and PVA-coated $\mathrm{Fe} 3 \mathrm{O} 4$ nanoparticles synthesized under N2 gas. J Magn Magn Mater 324: 4143-4146.

20. Khosroshahi ME, Ghazanfari L (2012) Synthesis and functionalization of SiO2 coated $\mathrm{Fe} 3 \mathrm{O} 4$ nanoparticles with amine groups based on self-assembly. Mater Sci Eng C 32: 1043-1049.

21. Duff DG, Baiker A, Edwards PP (1993) A new hydrogel of gold clusters. 1 formation and particle size variation. Langmuir 9: 2301-2309.

22. Pradhan P, Giri J, Rieken F, Koch C, Mykhaylyk O, et al. (2010) Targeted temperature sensitive magnetic liposomes for thermo-chemotherapy. J Control Release 142: 108-121.

23. Mayer LD, Bally MB, Cullis PR (1986) Uptake of adriamycin into large unilamellar vesicles in response to a $\mathrm{pH}$ gradient. Biochim Biophys Acta 857: 123-126.

24. Nie Y, Ji L, Ding H, Xie L, Li L, et al. (2012) Cholesterol derivatives based charged liposomes for doxorubicin delivery: preparation, in vitro and in vivo characterization. Theranostics 2: 1092-1103.

25. Kulshrestha P, Gogoi M, Bahadur D, Banerjee R (2012) In vitro application of paclitaxel loaded magnetoliposomes for combined chemotherapy and hyperthermia. Colloids Surf B Biointerfaces 96: 1-7.

26. Liu H, Hou P, Zhang WX, Wu J (2010) Synthesis of monosized core-shell $\mathrm{Fe} 3 \mathrm{O} 4 / \mathrm{Au}$ multifunctional nanoparticles by PVP-assisted nanoemulsion process. Colloid Surf A 356: 21-27.
27. Hirai H, Yakura N (2001) Protecting polymers in suspension of metal nanoparticles. Polym Adv Technol 12: 724-733.

28. Xu Z, Hou Y, Sun S (2007) Magnetic core/shell Fe3O4/Au and Fe3O4/Au/Ag nanoparticles with tunable plasmonic properties. J Am Chem Soc 129: 86988699.

29. Floris A, Ardu A, Musinu A, Piccaluga G, Fadda AM, et al. (2011) SPION@ liposomes hybrid nanoarchitectures with high density SPION association. Soft Matter 7: 6239-6247.

30. Wang F, Wang YC, Dou S, Xiong MH, Sun TM, et al. (2011) Doxorubicintethered responsive gold nanoparticles facilitate intracellular drug delivery for overcoming multidrug resistance in cancer cells. ACS Nano 5: 3679-3692.

31. Viroonchatapan E, Sato H, Ueno M, Adachi I, Murata J, et al. (1998) Microdialysis assessment of 5-fluorouracil release from thermosensitive magnetoliposomes induced by an electromagnetic field in tumor-bearing mice. J Drug Target 5: 379-390.

32. Yatvin MB, Mühlensiepen H, Porschen W, Weinstein JN, Feinendegen LE (1981) Selective delivery of liposome-associated cis-dichlorodiammineplatinum(II) by heat and its influence on tumor drug uptake and growth. Cancer Res 41: 1602-1607.

33. Woo J, Chiu GN, Karlsson G, Wasan E, Ickenstein L, et al. (2008) Use of a passive equilibration methodology to encapsulate cisplatin into preformed thermosensitive liposomes. Int J Pharm 349: 38-46.

34. Burke AR, Singh RN, Carroll DL, Wood JC, D'Agostino RB Jr, et al. (2012) The resistance of breast cancer stem cells to conventional hyperthermia and their sensitivity to nanoparticle-mediated photothermal therapy. Biomaterials 33: 2961-2970.

35. Osman AM, Bayoumi HM, Al-Harthi SE, Damanhouri ZA, Elshal MF (2012) Modulation of doxorubicin cytotoxicity by resveratrol in a human breast cancer cell line. Cancer Cell Int 12: 47.

36. Valeriote F, Lin Hs (1975) Synergistic interaction of anticancer agents: a cellular perspective. Cancer Chemother Rep 59: 895-900.

37. Koehn H, Magan N, Isaacs RJ, Stowell KM (2007) Differential regulation of DNA repair protein Rad51 in human tumour cell lines exposed to doxorubicin. Anticancer Drugs 18: 419-425.

38. Aroui S, Brahim S, Waard MD, Kenani A (2010) Cytotoxicity, intracellular distribution and uptake of doxorubicin and doxorubicin coupled to cellpenetrating peptides in different cell lines: a comparative study. Biochem Biophys Res Commun 391: 419-425.

39. Prasad NK, Rathinasamy K, Panda D, Bahadur D (2007) Mechanism of cell death induced by magnetic hyperthermia with nanoparticles of ?-MnxFe2-xO3 synthesized by a single step process. J Mater Chem 17: 5042-5051.

40. George KC, Singh BB (1982) Synergism of chlorpromazine and hyperthermia in two mouse solid tumours. Br J Cancer 45: 309-313.

41. Massart C, Barbet R, Genetet N, Gibassier J (2004) Doxorubicin induces Fasmediated apoptosis in human thyroid carcinoma cells. Thyroid 14: 263-270. 